\title{
Adoption of offset manifold design in hillside drip irrigation system using treated sewage water-the case of Hawassa University main campus, Ethiopia
}

\begin{abstract}
This paper deals with how best the underutilized resource of treated sewage water can be utilized productively for nearby hillside irrigation with drip irrigation avoiding environmental degradation. Design analysis was performed to adopt the offset and split manifold designs for drip irrigation system in different land slopes to achieve better uniformity of application. For land with slopes of 5, 8, 10 and 12 percent, the offset manifold design is recommended for having uniform manifold diameter. Split manifold design is feasible up to 5 percent land slope with manifold mainline junction at the centre and beyond this slope the junction should be located other than midpoint. Rainfall analysis, crop water demand and sewage water availability reveal exciting opportunities for water productivity enhancements in rainfed agriculture by integrating components of water management within the context of rainfed farming through sewage water harvesting and supplemental irrigation for dry spell mitigation.
\end{abstract}

Volume 2 Issue 2 - 2015

\section{Kannan Narayanan}

School of Bio systems and Environmental Engineering, Hawassa University, Ethiopia

Correspondence: Kannan Narayanan, School of Bio systems and Environmental Engineering, Hawassa University, Ethiopia,Tel 251919155491,Email kannan051968@yahoo.co.in

Received: November 10, 2014 | Published: April 08, 2015

Keywords: crop water, drip irrigation, hill side irrigation, manifold design, rainfall, sewage water

\section{Abbreviations: STP, sewage treatment plant}

\section{Introduction}

Against the background of the rapid decline in irrigation water potential due to climate change and low water-use efficiency in the flood (conventional) method of irrigation, drip irrigation becomes a feasible choice. Besides saving a substantial amount of water, it also helps to increase the productivity of crops. The issue of rainfall variability is more critical for agricultural lands located on hills that, unlike the marshlands, lack water storage and for which reason support only limited farming during dry seasons. Ethiopia's cultivable land is about 13.2 million hectare. But the actual cultivated land is about 6 million hectare, which is $45 \%$ of the cultivable area. Dynamic and innovative action is needed to increase the actual cultivated area by transforming swamps and hill side lands into cultivable round the year. To achieve this goal, new land management technologies are to be adopted. Irrigation is kept as one of top priority area by Government of Ethiopia. From the existing cultivated area, only about 4 to 5 percent is irrigated. ${ }^{1}$ This is very low compared to other developing countries.

Irrigated agriculture will remain to be important for providing food and livelihood security to the fast growing population. Among the various techniques employed in areas with low rainfall and poor water resources (Arid and semi-arid regions) to conserve the existing water supplies put them to best use, drip irrigation is one of the latest innovations. ${ }^{2}$ To cope with increasing irrigated agriculture and decreasing rainfall due to climate change, unexploited new water resources needs to be tapped. Waste water utilization for agriculture is a feasible and viable option needs serious attention since it has dual purpose of reaping economic benefits and preventing environmental degradation.

Continuous application of waste water on agricultural land affects soil hydraulic properties. ${ }^{3}$ But this impact is more on flat lands rather than hillside lands. Waste water and the adjoining hillside land have been taken as a research subject for effective resource utilization in order to improve land productivity and environmental conditions. The adjoining hill side lands which are more susceptible to soil moisture stress due to short spells of rainfall failure resulting reduced crop yield. This problem is more pronounced in shallow rooted crops and annual crops. In general if this problem is not paid serious attention, it will hamper year round cultivation of hill side lands. Moreover, due to steep slope and porous subsurface strata of hill side lands, water harvesting and moisture retention potential of hill side lands accelerates fast drying of soil causing moisture stress. So, supplemental irrigation becomes inevitable to facilitate year round cultivation.

In hill side lands, drip irrigation system has to be designed considering the land slope in order to eliminate high pressure variation which results non uniform application of irrigation water. Normally on hill side lands, drip laterals are to be laid along the contour lines and obviously, the manifolds should run across the land slope leasing to high pressure variation in the manifold and this leads to limitation of manifold length to achieve water application uniformity. To find a solution for this problem appropriate design concepts of drip irrigation are analysed with reference to the study area. The main objective of the study is to adopt the offset and split manifold designs for drip irrigation system in different land slopes for sugarcane cultivation using waste water. The specific objectives of this study comprises analysing climate conditions, estimating crop water and irrigation demand and evaluating offset and split manifold design on various land slopes. The study is limited to existing land slopes and available sewage water quantity presuming water quality from the existing oxidation and polishing tanks of sewage treatment meets the standards of irrigation water. Additional pressure sand filters may be added to improve the quality matching drip irrigation standards. 


\section{Materials and methods}

\section{Climate and topography}

Hawassa has warm temperature which varies between $10^{\circ} \mathrm{C}$ in winter and $30^{\circ} \mathrm{C}$ in summer. The mean annual precipitation is $958 \mathrm{~mm}$. Hawassa is situated at the Eastern shore of Lake Hawassa close to the eastern fault belt of the central part of the Main Ethiopian Rift Valley in a large volcano-tectonic collapse. It lies on the plain between Lake Hawassa and Chelelaka wetland with general slope towards Lake Hawassa. The average elevation at is $1700 \mathrm{~m}$ and that of the lake surface is $1680 \mathrm{~m}$. Rain is more intensive during the four rainy months of June to September such that more than $80 \%$ of the rain falls during this period. The university farm land is formed of gentle and undulating hills, surrounding by ranges of hills with different altitudes.

\section{Sewage water}

Ponds and tanks are one of storage options and combinations that can be considered for managing increasing water resources variability. ${ }^{4}$ From the student's hostel buildings which accommodate more than 10,000 students, average sewage discharge of 5.8 to $8.1 \mathrm{~L} / \mathrm{s}$ (500 to $700 \mathrm{~m}^{3} / \mathrm{d}$ ) litre per second is estimated (Directorate of constructions, $\mathrm{HU})$. This water is collected by many septic tanks constructed as part of primary anaerobic treatment removing macro particles. The effluent from these septic tanks is delivered to sewage treatment plant (STP) located at a distance of around $1 \mathrm{~km}$. The STP comprises of a series of lined earthen tanks of different capacities starting from Primary sedimentation tank followed by oxidation and polishing tanks. The sewage water is treated both by physical and biological treatment to reduce the suspended solids and Biochemical oxygen demand to the acceptable levels. The treated effluent is then delivered to irrigate the low lying agriculture lands. Since all the rainwater from the surrounding high lands accumulates in the low lands thus making them water logging causing nuisance and environmental pollution and affecting the crop yield particularly during rainy season. July and August will be the summer vacation and during that period the effluent will not be available. So alternate source of water is needed and this can be met by using the existing tube wells for irrigation.

\section{Crop water requirements}

To estimate the crop water and irrigation water requirements for sugarcane crop, CROPWAT software for windows was used. The input climate parameters are taken from meteorological station at Hawassa. Crop and soil parameters are taken from FAO.

\section{Design of lateral}

The lateral length is chosen by dividing the field into two parts, as the manifold passes in the middle of the land. Discharge into this pipe depends on the number of dripper operating on it and their operating discharge. The diameter of lateral pipe is selected so that the difference in discharge between emitters operating simultaneously will not exceed 10 percent. ${ }^{5}$ The lateral diameter to produce the friction loss is calculated using Hazen William's formula.

Head loss in lateral: Head loss is calculated using Hazen -William formula

$$
\Delta H l=1.21 \times 1010(Q / C) 1.852 \times D-4.87 \times L f . \times F \ldots .(1)
$$

Where, $\Delta \mathrm{H}_{1}$ - the friction head loss in metre,
Q - Lateral discharge in lit/sec,

D - Diameter in $\mathrm{mm}$,

L-Lateral pipe length in $\mathrm{m}$

C-Friction coefficient

$\mathrm{L}_{\mathrm{f}}$-Equivalent lateral length and

F-Multiple outlets Coefficient

Pressure variation in laterals: About $3 / 4$ of the total friction loss occurs in the first half of the lateral line and $1 / 4$ in the second half. Therefore the pressure requirement at the entrance of lateral $\left(\mathrm{H}_{\mathrm{m}}\right)$ is equal to the average design pressure + an equivalent of $3 / 4$ of the total loss of pressure in the lateral + elevation change along lateral

Percent variation in pressure $=P \max -P \min P a \ldots$

Where: $\mathrm{P}_{\mathrm{a}}$ - operating pressure, $\mathrm{P}_{\min }$ and $\mathrm{P}_{\max }$ are maximum and minimum pressure along the lateral

\section{Manifold design}

It is commonly accepted practice to orient the pipe network so that the laterals traverse the minimum slope possible (on the contour). The manifolds, therefore, are likely to lie along maximum slopes and thereby necessitate special consideration during the design procedure. Two basic manifold design strategies can be employed. The first maintains the manifold pipe to single diameter by offsetting the main or submain-manifold junction uphill. The objective of this design is to keep the minimum pressure in both directions equal so the design standard or allowable pressure variation is satisfied. The second approach is to locate the main or submain-manifold junction at the manifold mid-point and use two pipe diameters to achieve the same objective.

Offset manifold design: The auxiliary will be connected to the manifold at a point where the minimum pressure in both sections of the manifold will be the same. For instance, if the manifold is lying on level ground, the connection point will be midway along the manifold. For manifolds on a slope, the connection point will be somewhat towards the manifold end with the highest elevation. ${ }^{6}$ The location of the connection point and the manifold pipe diameter involve a series of trial and error calculations. The first step is to divide the manifold length into the reach flowing uphill $\mathrm{L}_{1}$ and the reach flowing downhill $\mathrm{L}_{2}\left(=\mathrm{L}_{\mathrm{m}}-\mathrm{L}_{1}\right)$ where $\mathrm{L}_{\mathrm{m}}$ is the total manifold length (Figure 1). The discharge diverted into both pipes is estimated by assuming the average lateral discharge. The number of intervals in both directions is:

$$
N 1=L 1 S l \ldots .(3)
$$

$N 2=L 2 S l \ldots .(4)$

The discharge in both directions is:

$$
\begin{aligned}
& Q 1=N 1 \times Q L \ldots .(5) \\
& Q 2=N 2 \times Q L \ldots .(6)
\end{aligned}
$$

\section{Where $\mathrm{Q}_{\mathrm{L}}$ - Average lateral discharge}

Setting the pressure heads at the two ends of the manifold to be equal $\left(h_{1}=h_{2}\right)$, the difference between the uphill and downhill head losses must be equal to the difference in elevation between the ends of the manifolds. 


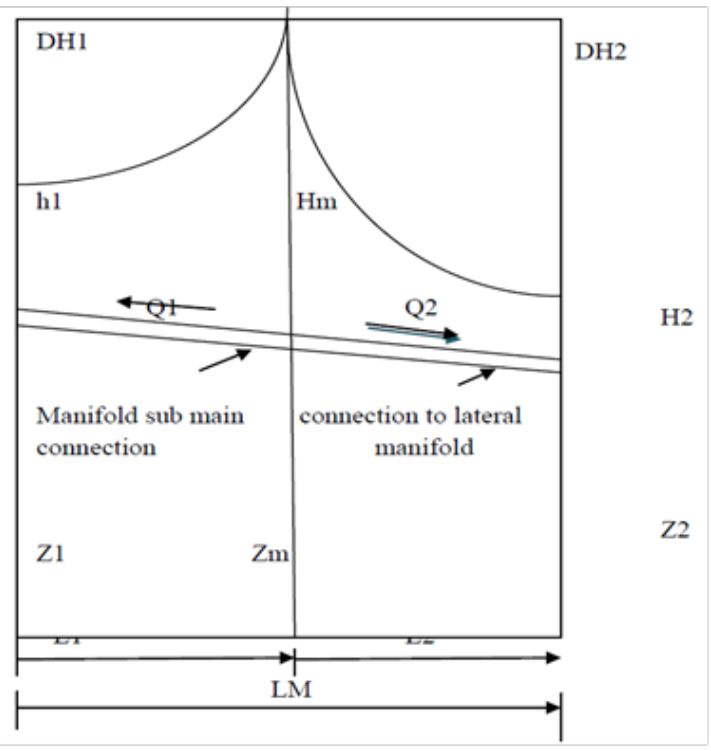

Figure I Lateral inlet pressure heads along a sloping manifold.

$$
\triangle H 1+Z 1=\Delta H 2+Z 2 \ldots .(7)
$$

The allowable head loss for horizontal manifolds can be taken as $45 \%$ of the allowable pressure variation in the network which is usually taken as $0.2 \mathrm{H}_{\mathrm{o}}$ where $\mathrm{H}_{\mathrm{o}}$ is design system operating pressure. Hence,

Hfallowable $=0.45(0.20 H o)=0.09 H o \ldots . .(8)$

For pipes running uphill:

hfallow $\geq \Delta H 1+\Delta Z 1 \ldots .(9 a)$ or $\Delta H 1 \leq$ hallow $-L 1 . S m \ldots . .(9 b)$

In which $\mathrm{S}_{\mathrm{m}}$ is the uniform manifold slope.

For pipes running down hill:

hfallow $\geq \Delta H 2-\Delta Z 1$....(10a) or $\Delta H 2 \leq$ hfallow $+L 2 . S m$...

After setting $\mathrm{L}_{1}$ and $\mathrm{L}_{2}$, knowing $\mathrm{H}_{\mathrm{o}}$ and uniform manifold slope, allowable head loss $\left(\mathrm{hf}_{\text {allowable }}\right.$ ) has been calculated. The calculate the friction head loss in the uphill reach $\Delta \mathrm{H}_{1}$, using equation with same units knowing $\mathrm{N}_{1}, \mathrm{~L}_{1}$ and $\mathrm{Q}_{1}$, determine the manifold diameter $\mathrm{D}_{\mathrm{m}}$ to produce friction $\Delta \mathrm{H}_{1}$, specifically.

\section{$D m=[(1 \Delta H 1 /) 1.21 \times 1010(Q 1 C) 1.852 \times L 1 . F 1] 0.2053 \ldots . .(11)$}

In which $\Delta \mathrm{H}_{1}$ - friction head loss uphill reach in meter $\mathrm{Q}_{1}$ - uphill reach discharge, lit/sec, $\mathrm{L}_{1}$ - uphill length in $\mathrm{m}$ Knowing $\Delta \mathrm{H}_{1}, \mathrm{Z}_{1}$ and $\mathrm{Z}_{2}$ determine the friction head loss in the down slope reach $\Delta \mathrm{H}_{2}$. Using equation (11), determine the manifold diameter which will produce $\Delta \mathrm{H}_{2}$. If the manifold diameters computed for the uphill and downhill sections are different, the value of $\mathrm{L}_{1}$ and $\mathrm{L}_{2}$ are modified until the difference between the iterations for diameter is negligible.

Split manifold design: The total manifold length is divided by two to get $\mathrm{L}_{1}$ and $\mathrm{L}_{2}$. The friction head loss in the uphill and downhill reaches is obtained from equation:

$\Delta H 1 \leq$ hfallowable - L1.Sm....(12) hill

In which $\mathrm{S}_{\mathrm{m}}$ is the uniform manifold slope for pipes running down

\section{$\Delta H 1+Z 1=\Delta H 2+Z 2$}

Setting the pressure heads at the two ends of the manifold to be equal $\left(h_{1}=h_{2}\right)$, the difference between the uphill and downhill head losses must be equal to the difference in elevation between the ends of the manifolds. The manifold diameter for the uphill reach and downhill reach can be calculated separately using Hazen - William formula.

\section{Results and discussion}

The concept of offset and split manifold design is applied on a field measuring 0.8 ha area with different slopes available on the farm land adjoining the oxidation ponds of Hawassa university sewage treatment system. Both the designs are analysed and discussed under different slopes regarding their applicability.

\section{Rainfall}

Annual average rainfall considering 5,10 and 20year data shows a decreasing trend due to impact of climate change. The rate of decrease in rainfall is $1.76 \%$ and $8.9 \%$ based on 10 and 5years average. This implies that the rate of decrease is increasing year by year resulting severe impact on agriculture and land management practices. To cope with this decline in rainfall, suitable strategies should be followed in crop scheduling and water management. Owing to increasing population and food demand new water resources and appropriate water application methods need to be evolved. Figure 2 shows that 5 year monthly average rainfall reached a new low figure in June and September, alarming possibility of short spells of water scarcity. In the month of May, it reached highest value of $135 \mathrm{~mm}$. These extremities in both high and low ends lead to ore vulnerability to drought and flood damages. Appropriate new design concepts for irrigation water application needs to be adopted to handle the ill effects of climate change.

For irrigation system design, peak crop water demand of sugarcane and effective rainfall are to be considered. Considering 5year averages compared to 20year average values of these parameters are absolutely different (Figure 3). To cope with the existing short spells of water scarcity, it is recommended to design the irrigation system considering 5 year average values of both rainfall and other climate parameters to estimate crop water demand and irrigation demand.

\section{Impact of planting season}

For 5year average of climate data, according to the time of planting of sugarcane irrigation demand varies. Being a perennial crop, water demand of each crop stage interacts differently with rainfall and results typical irrigation demand. Two cases are analysed, one is planting in February and another planting in June. Figure 4 shows monthly irrigation demand for planting in February with 5year average data. For both 5year and 20year average climate data, peak crop water demand is atleast $47 \%$ more than that of planting in June.

Main pipe design discharge requirement according to CROPWAT is $12 \mathrm{~L} / \mathrm{s} /$ ha for planting in June whereas it is $14.7 \mathrm{~L} / \mathrm{s} /$ ha for planting in February. So, planting in June is more affordable and favourable for crop and irrigation economy. Due to less water consumption during initial crop stages and reasonable rainfall, irrigation demand is nil during June, July and August. This happens if planting is done in June (Figure 5). Whereas in case of planting done in February, irrigation is to be supplied during most months of the year resulting higher irrigation system and operating costs. Shifting of planting date due to 
effects of climate change will result in increased irrigation demand. For timely planting farmers need to have independent water source for irrigation. This demands intervention of ground water or other new water resources which are not tapped so far. In the present area of study, sewage water which is ineffectively utilised can be converted into more productive by adopting innovative water management techniques.

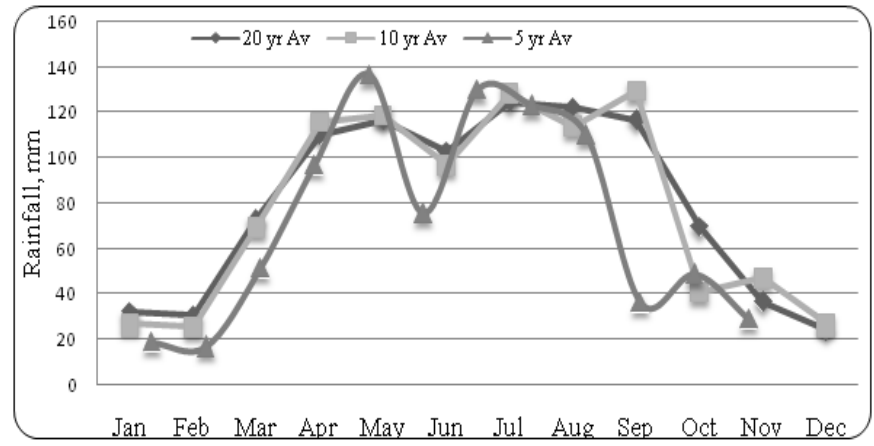

Figure 2 Variation of Monthly average rainfall.

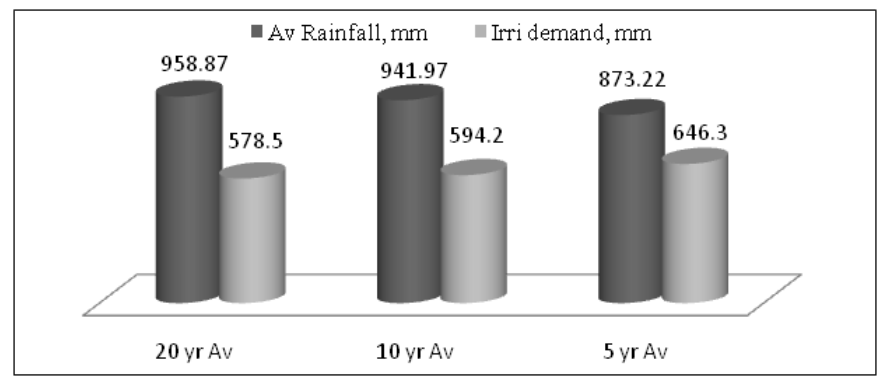

Figure 3 Average Rainfall and Irrigation demand.

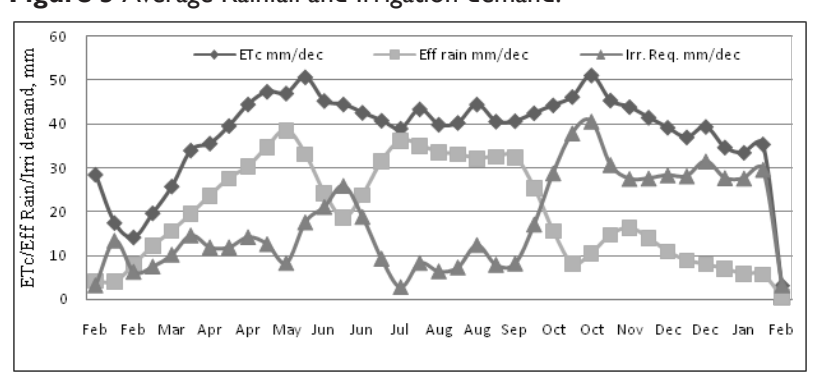

Figure 4 Monthly Crop water and irrigation demand.

\section{Irrigation demand of sugarcane}

Being a long duration crop, it needs total crop water demand of $1400 \mathrm{~mm}$ for Hawassa climate conditions. Both 5year and 20year average monthly rainfall data are analysed to estimate effective rainfall and irrigation demand. Considering medium sandy loam soil, the net irrigation water to be applied in the root zone to replenish $30 \%$ depletion is calculated as $48.6 \mathrm{~mm}$. For $90 \%$ irrigation efficiency, gross irrigation depth of $54 \mathrm{~mm}$ is to be applied. Considering peak crop water demand of $5.5 \mathrm{~mm} /$ day for the case of 5 year average climate data, the root zone can retain moisture to favour 9days irrigation interval. But to be more efficient, drip irrigation needs more frequency of water application. So, 3days of irrigation interval is selected for the design of the drip irrigation system. Peak irrigation demand of $2.7 \mathrm{~mm} /$ day is observed for 20year average data with planting date in January whereas $4.6 \mathrm{~mm} /$ day is observed when planting is in June. Maximum irrigation demand of $795 \mathrm{~mm}$ is needed for 5 year average data whereas it is $7.5 \%$ less for $20 y e a r$ climate data. This clearly reveals recent climate conditions demand increased irrigation as compared to the past years. Considering the effect of climate change, designing the irrigation system to match recent average climate data of atleast 5years will be a more appropriate. This will equip our irrigation system better adapted to climate changes.

\section{Sewage water}

From the effluent treatment plant of Hawassa university student's residential buildings, average treated effluent discharge of 10litres/ $\mathrm{sec}$ is currently underutilized. Prospective of using effluent water for irrigation is well justified by low biological oxygen demand and suspended solids which are well within the permissible limit of 20 and 30ppm. Since the sewage is subjected to septic tank for sedimentation and anaerobic preliminary treatment to reduce the biological and suspended impurities. After this, the effluent is further treated with sedimentation, oxidation and polishing tanks for natural process of sedimentation and anaerobic biological treatment. The treated water is found as clear and odourless and found as suitable for irrigation purpose. Since the water availability is limited, high efficient irrigation method of drip irrigation system is selected. This will envisage irrigation of 5.5 hectares of nearby hill side lands with addition of water treatment by disc/pressure sand filter of 200 micron. The suspended solids of treated effluent are rich in readily available nutrients essential for plant growth and increased yield. According to Bates et al., ${ }^{7}$ observational records and climate projections provide abundant evidence that freshwater resources are vulnerable and have the potential to be strongly impacted by climate change, with wide-ranging consequences on human societies and ecosystems" e.g. devastating floods and droughts of increasing frequency and magnitude in different regions, with severe damages to agriculture, livelihoods of poor farmers and food security of nations. To cope with very low Storage-Drought Deficit Index (i.e. how much of the longterm annual hydrological drought deficit is satisfied by the existing storage capacity in a county) of $0.05 \%$ for Ethiopia,${ }^{8}$ utilization of sewage water becomes inevitable to mitigate vulnerabilities due to climate change. The proposed strategy of using sewage water for irrigation will not only use water farmer-friendly but also environment friendly and reduces vulnerability of food production system to climate change.

\section{Drip irrigation}

Emitters and laterals: For sugarcane drip irrigation system is designed with single row inline drip laterals with $1.2 \mathrm{~m}$ spacing. Wider lateral spacing is not considered despite its access to farm implements. Since the study area is hill side land, possibility of application of farm mechanization is limited particularly in un-terraced hill side lands. Inline dripper of $4 \mathrm{~L} / \mathrm{h}$ is selected with operating pressure of 1.5 bar. This can meet 3 days peak irrigation demand of sugarcane in 3 hrs 45 minutes irrigation duration. In case of hill side lands where normally steep slopes are expected, the laterals are to be laid along the contour and obviously the manifolds run along the slope gradient. Required number of laterals needed is 42 with lateral spacing of $1.2 \mathrm{~m}$. Considering the field of $160 \mathrm{mx} 50 \mathrm{~m}$ in which the length is equal to the length of one lateral and the width has been chosen as the length of manifold. The number of plants irrigated by one lateral is 200 plants. Accordingly lateral discharge is calculated as $0.22 \mathrm{~L} / \mathrm{s}$. Always the manifold is placed at the predominant slope so that laterals are perpendicular to this to reduce the head loss. With $20 \mathrm{~mm}$ diameter 
of lateral pipe, the head loss is $1.43 \mathrm{~m}$ which is within the allowable limit of $1.65 \mathrm{~m}$. Since pressure variation in lateral is found as $9.5 \%$ which is less than the allowable limit of $10 \%$, the selected diameter is acceptable.

Since the lateral is laid along the contour zero slopes is considered. But this may not be the case always. Many times the laterals will be laid along the slope and depending on the degree of the slope, design decision will be taken. Under such conditions the slopes are to be verified whether it is steep or not based on land elevation and operating pressure. Steep slope occurs when the change in land elevation is more than $30 \%$ of the operating pressure of the emitter. Under steep slope conditions normally the laterals should be laid down hill in such a way that the friction loss with a particular pipe diameter should compensate the increase in pressure due to land elevation. Laying the laterals in uphill direction should not be practiced provided the land is steel slope. Laying the lateral in the uphill direction if at all needed under specific circumstances, it should be done only when the slope is mild. Closed drip irrigation circuits have been used in attempts to overcome the drop in pressure at the end of the lateral line of drip irrigation system. ${ }^{9}$ It can be a good option to improve the studied hydraulic characteristics like pressure head, friction loss, flow velocity, lateral discharge, uniformity coefficient and efficiency of both water and fertilizer. But it needs additional pipes and increases the cost of the system. So, appropriate design following offset manifold will be more ideal than closed drip irrigation circuits.

\section{Design of manifold}

Since the manifold of hill side irrigation system needs to be laid along the existing land slope, location of main pipe-manifold junction decides the pressure distribution in manifold pipe which ultimately influence the distribution uniformity. But its influence depends on the degree of land slope. As presented in the methodology section both offset and split manifold designs can be practiced in manifold design. Considering $45 \%$ of total allowable friction loss, for manifold it come to $1.35 \mathrm{~m}$. With $90 \mathrm{~mm}$ PVC pipe under manifold discharge of $8.4 \mathrm{~L} / \mathrm{s}$, actual friction loss comes to $0.37 \mathrm{~mm}$ which is less than allowable limit. It also shows that the pipe size still can be reduced since the available head loss is far more than the actual. Under flat land conditions no matter where the location of main pipe-manifold junction is.

Offset manifold design: The main pipe will be connected to the manifold at a point where the minimum pressure in both sections of the manifold will be the same. The diameter of the uphill and downhill reach comes to 46 and $44 \mathrm{~mm}$ respectively. The location of the connection point and the manifold pipe diameter involve a series of trial and error calculations. For the previous trials taken at different distances from the uphill(at $8^{\text {th }}$ lateral, $12^{\text {th }}$ ) the diameters found were not the same i.e. no inlet position can give the equal diameters at the uphill end and downhill end. For the last trial the inlet position taken at $10^{\text {th }}$ lateral from the uphill end gives the approximately same diameters at the uphill and downhill ends when the connection point is $12 \mathrm{~m}$ from uphill (Figure 6). No other trial can be made beyond $12 \mathrm{~m}$ from the uphill end, if it is performed beyond this distance the friction loss will be negative for uphill manifold indicating pressure variation going beyond the acceptable limit and needs pressure regulator.

For different slopes viz. $12 \%, 8 \% 5 \%$ with suitable junction positions, the offset design is performed. It indicates that the appropriate diameters found for $12 \%, 8 \%$ and $5 \%$ were $40 \& 42 \mathrm{~mm}$,
$43 \& 44 \mathrm{~mm}$ and $44 \& 44.5 \mathrm{~mm}$ respectively for uphill and downhill pipes. The objective of offset design is to keep the minimum pressure in both directions equal. For more accurate calculations, a computer program can be written since it involves much iteration. It is observed that for higher land slope, the junction approaches the uphill end. Under higher slope conditions, the downhill length will be more than the uphill length and beyond certain level pressure regulator is must to have same pipe diameters on both sides. Since pressure regulators are expensive, it is suggested to go for different diameters in both uphill and downhill sides. The manifold diameters computed for the uphill and downhill sections are different, and no other trial can be made beyond $6 \mathrm{~m}$ from the uphill end. If it is performed, the friction loss will be negative for uphill manifold. According to Mizyed et al., ${ }^{10}$ the main factors affecting trickle irrigation system are: pressure variations caused by elevation changes, friction head losses throughout the pipe network, emitter sensitivity to pressure and irrigation water temperature changes, and emitter clogging. Similarly, according to the manufacturer's coefficient of emitter variation $(\mathrm{CVm})$, have been developed by ASAE, ${ }^{11} \mathrm{CVm}$ values below $10 \%$ are suitable and $>20 \%$ are un-acceptable. The emitter discharge variation rate (qvar) should be evaluated as a design criterion in trickle irrigation systems; qvar $<10 \%$ may be regarded as good and qvar $>20 \%$ as unacceptable. ${ }^{12,13}$ To keep the emitter discharge variation within the limit it is necessary to maintain pressure variation within the limit of $20 \%$. For this purpose, the objective of offset design is to keep the minimum pressure in both directions equal but in this case the design standard or allowable pressure variation is not satisfied. So the offset manifold design should not be utilized for the slope of $22 \%$ and split manifold design is recommended for this slope and utilization two different diameter of $45 \mathrm{~mm}$ and $30 \mathrm{~mm}$ respectively for uphill and downhill manifold sections. Location of main pipe-manifold junction from uphill for 5, 8, 10 and 12\% are 16.8, 13.2, 12 and 9.6m respectively.

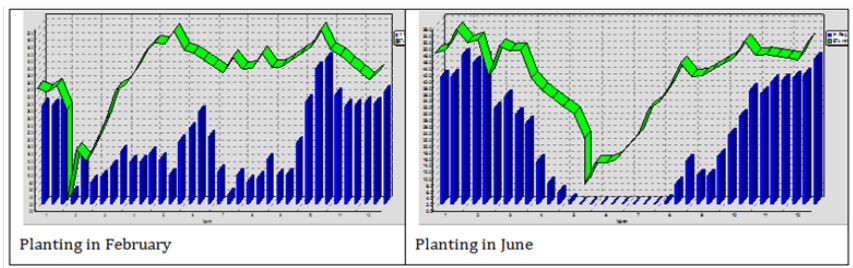

Figure 5 Seasonal Variation of crop water demand and irrigation demand.

Split manifold design: The manifold length is divided into two equal parts to get $\mathrm{L}_{1}$ and $\mathrm{L}_{2}$ and two different diameters are used so that the design standard or allowable pressure variation is satisfied. For our case, the inlet position is at $25 \mathrm{~m}$ from uphill end, at $21^{\text {st }}$ lateral. If the slope is $12 \%, 10 \%, 8 \%$ the allowable head loss in the uphill reach is negative; the variation of the pressure will be high for supplying water from the mainline manifold junction to the uphill end. At $5 \%$ slope it is found that the allowable head loss in the uphill is positive and the uphill and downhill pipe diameters are 75 and $40 \mathrm{~mm}$ respectively (Figure 7). Beyond this slope the allowable head loss at uphill end is negative indicating that the main pipe - manifold junction cannot be at midpoint of the manifold. Gerrish ${ }^{14}$ indicated that the relation between the flow rate and the pressure head is nonlinear in the transition and the turbulent flow types. It is also essential to incorporate pipe components into the hydraulic network analysis by adding their contribution to the nodal equations instead of treating them as separate items. Split manifold design is simple and demands two different pipe diameters 
of manifold. This leads to different friction loss and flow velocity in the two manifolds resulting water application more differently than offset manifold design. Normally offset design ensures higher uniformity of application than the split design

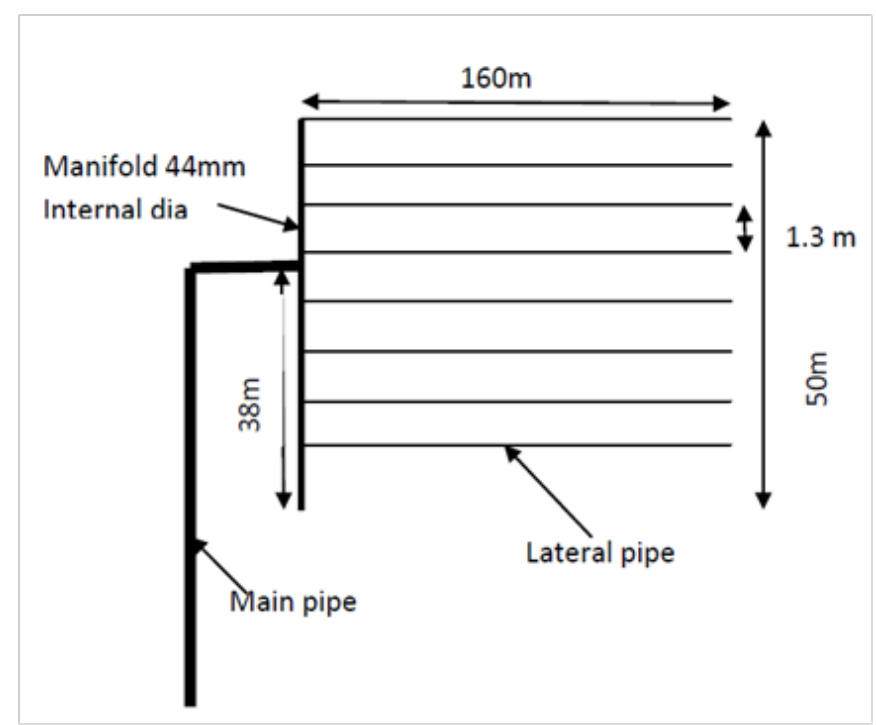

Figure 6 Offset manifold on $5 \%$ land slope.

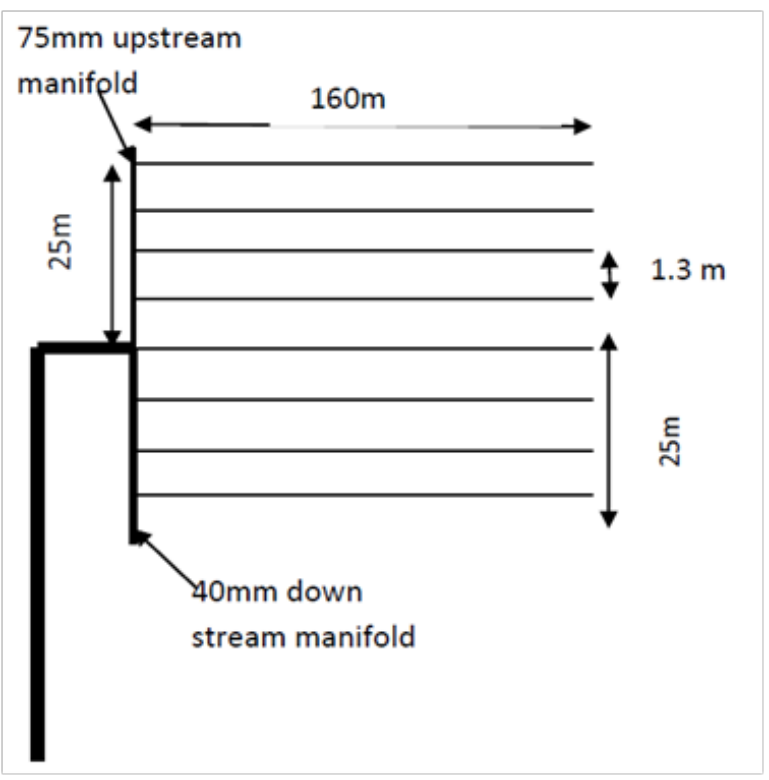

Figure 7 Split manifold on 5\% land slope.

\section{System capacity}

To supply $8.4 \mathrm{~L} / \mathrm{s}$ to the irrigation system, main pipe of $110 \mathrm{~mm}$ diameter is needed resulting $0.9 \mathrm{~m}$ friction loss in $150 \mathrm{~m}$ length. With total pressure head requirement of $32.5 \mathrm{~m}$, power of $4.5 \mathrm{KW}$ is needed to lift water and feed to the irrigation system. Based on elevation head, the energy cost varies making the pressure irrigation system to perform uniquely with different crops. Deep rooted crops can tolerate more than shallow rooted crops which demands irrigation more frequently. Type of crop, land elevation and planting period all together controls the feasibility of drip irrigation system in hill side agriculture. Energy is needed in pipe systems not only to pump water from the source to the pipe but also to overcome the energy losses due to friction as water flows down the pipe. Losses can increase as the pipe ages and becomes rougher inside through continued use. For these reasons the losses in the distribution system should be kept low at the design stage by choosing pipe diameters that are large enough for friction to not dominate the operation of the system at some later date. As a guideline, energy losses in the pipes should be less than $30 \%$ of the total pumping head. Pimente ${ }^{15}$ indicated that irrigation accounts for $13 \%$ of the agricultural energy consumption. There have been some attempts to power irrigation systems with renewable energies, but most of the resulting systems are designed for large farms and the cost for such systems is usually high and practically not available for developing countries like Ethiopia despite huge potential. So designing drip irrigation system particularly for hill side lands shall follow offset or split manifolds designs to reduce pipe length and pressure variation along the pipe. By this uniformity of water application can be achieved with less pumping capacity due to reduced friction loss in the irrigation system.

\section{Conclusion}

Prevailing climate conditions in Hawassa needs supplemental irrigation particularly for cultivation of annual crop like sugarcane. Irrigation demand is influenced by planting season. Sugarcane planting in June demands less irrigation compared to February. Analysis of climate data reveals that in the past 5years rainfall is in decreasing trend and supports positively to consider the design of irrigation system based on 5years data rather than 20years data. Sewage water from Hawassa University can be effectively utilized for irrigating sugarcane in the adjoining hill side lands near effluent treatment plant. By using drip irrigation about 5 hectares can be irrigated to meet the peak irrigation demand of sugarcane. Both offset and split manifold design practices can be adopted with different limitations. For land with slopes of 5, 8, 10 and 12percent, the offset manifold design is recommended for having uniform manifold diameter. Split manifold design is feasible up to 5 percent land slope with manifold mainline junction at the centre and beyond this slope the junction should be located other than midpoint. Analysis of rainfall, crop water demand and sewage water availability reveals exciting opportunities for water productivity enhancements in rainfed agriculture by integrating components of water management. Detailed analysis is needed for feasibility of lift irrigation with different crops under different altitudes to derive suitable solution for hill side irrigation.

To strengthen water availability in addition to sewage water, it is recommended to construct rainwater harvesting ponds to collect runoff from the adjoining hillsides for combined use of both rainwater and sewage water adopting lift irrigation to support hill land agriculture. This needs further detailed studies on water exploration to ensure its availability. Elevation difference of more than $50 \mathrm{~m}$ between the low lying flat land and hillside lands in most of the cases questions feasibility of lift irrigation. Detailed analysis is needed for feasibility of lift irrigation with different crops under different altitudes to derive suitable policy for hill land irrigation and cropping pattern. Feasible zones of altitudes for different crops should be demarcated on hill land based on its economical viability. It is recommended to go for commercial crops in higher altitudes of hill to make the irrigation system feasible. Beyond the feasible altitude, runoff harvesting in farm 
ponds using micro catchment should be practiced for supplemental irrigation.

\section{Acknowledgements}

None.

\section{Conflict of interest}

The author declares no conflict of interest.

\section{References}

1. Seleshi BA, Erkossa T, Namara RE. Irrigation potential in Ethiopia: Constraints and opportunities for enhancing the system. Colombo, Sri Lanka: International Water Management Institute; 2010.

2. Mandal RC, Jana PK. Water Resource utilization and Micro-IrrigationSprinkler and Drip system. Khanna, New Delhi; 2003. p. 141-143.

3. Mustafa M, Bernd L. Proceedings of Third Annual research Conference. Ethiopia: Jimma University; 2012.

4. McCartney M, Smakhtin V. Water Storage in an Era of Climate Change: Addressing the Challenge of Increasing Rainfall Variability. Colombo, Sri Lanka: International Water Management Institute Blue Paper; 2010.

5. Israelsen OW, Hansen VE. Irrigation Principles and Practices. Inc. New York, USA: John Wiley and Sons; 1962. 447 p.

6. Keller J, Karmeli D. Trickle Irrigation Design. Rain Bird sprinkler Manufacturing corp. Glendora, California, USA; 1975. 133 p.

7. Bates BC, Kundzewicz ZW, Wu S, et al. Climate Change and Water. Technical Paper for the Intergovernmental Panel on Climate Change. IPCC Secretariat; 2008.

8. Eriyagama N, Smakhtin V, Gamage N. Mapping Drought Patterns and Impacts: A Global Perspective. International Water Management Institute Research Report 133. Colombo, Sri Lanka: International Water Management Institute; 2009.

9. Tayel M, Mansour H, Lightfoot D. Effect of different closed circuits and lateral line lengths on flow velocity and velocity head. Agriculture Science. 2012;3(4):531-537.

10. Mizyed N, Kruse EG. Emitter discharge evaluation of subsurface trickle irrigation systems. Transactions of the American Society of Agricultural and Biological Engineers. 1989;32(4):1223-1228.

11. American Society of Agricultural Engineers. EP405.1 FEB03. Design and installation of microirrigation systems. ASAE Standards, St. Joseph: ASAE; 2003. p. 901-905.

12. Wu IP, Gitlin HM. Hydraulics and uniformity for drip irrigation. $J$ the Irrigation and Drainage Division. 1973;99(2):157-168.

13. Camp CR, Sadler EJ, Busscher WJ. A comparison of uniformity measure for drip irrigation systems. Transactions of the American Society of Agricultural Engineers. 1997;40(4):1013-1020.

14. Gerrish PJ, Shayya WH, Bralts VF. An improved methods for incorporating pipe components into the analysis of hydraulics networks. Transactions of the ASAE. 1996;39(4):1337-1343.

15. Pimentel D, Giampietro M. Food, Land, Population and the U.S. Economy. USA: Carrying Capacity Network; 1994. 